Table 1

\begin{tabular}{|c|c|c|c|c|}
\hline DISEASE & STOPPED CAUSE & $\begin{array}{l}\text { BACK TO } \\
\text { Etanercept } \\
\text { original }\end{array}$ & $\begin{array}{c}\text { CONTINUE } \\
\text { Etanercept } \\
\text { original }\end{array}$ & $\begin{array}{c}\text { TIME UNTIL } \\
\text { SWITCH (meses) }\end{array}$ \\
\hline AS & $\begin{array}{c}\text { Reaction at the injection } \\
\text { site }\end{array}$ & Yes & Yes & 28 \\
\hline AS & Headache & Yes & Yes & 54 \\
\hline AS & Ineffecacy & Yes & Yes & 126 \\
\hline RA & Ineffecacy & Yes & No & 25 \\
\hline AS & Diarrhea & Yes & Yes & 87 \\
\hline RA & Ineffecacy & Yes & Yes & 37 \\
\hline PsA & Ineffecacy & No & No & 43 \\
\hline RA & Ineffecacy & Yes & Yes & 54 \\
\hline PsA & Ineffecacy & Yes & No & 93 \\
\hline PsA & Ineffecacy & No & No & 132 \\
\hline PsA & Ineffecacy & Yes & Yes & 62 \\
\hline RA & Ineffecacy & Yes & Yes & 142 \\
\hline RA & $\begin{array}{c}\text { Reaction at the injection } \\
\text { site }\end{array}$ & Yes & Yes & 51 \\
\hline RA & Ineffecacy & Yes & No & 56 \\
\hline PsA & Ineffecacy & Yes & No & 40 \\
\hline AS & Ineffecacy & Yes & Yes & 26 \\
\hline AS & Diarrhea & Yes & Yes & 48 \\
\hline
\end{tabular}

Disclosure of Interests: Vicente Aldasoro Speakers bureau: Roche, Abbvie, MSD, UCB, Pfizer, Menarini, Grunenthal, Gebro, Novartis, Janssen, Javier Mendizabal: None declared, Sara Perez Garcia: None declared, Guillen Sada Urmeneta: None declared, Juliana Restrepo Vélez: None declared, Natividad del Val del Amo: None declared, Inmaculada Paniagua Zudaire: None declared, Ricardo Gutiérrez Polo: None declared, Loreto Horcada: None declared, Laura Garrido Courel: None declared, C. Fito-Manteca: None declared DOI: 10.1136/annrheumdis-2020-eular.3279

\section{AB0273 1 PREDICTORS OF DRUG SURVIVAL OF BDMARDS IN BIO-NAIVE PATIENTS WITH RHEUMATOID ARTHRITIS (RA) DURING THE FIRST YEAR OF THERAPY.}

E. Aronova ${ }^{1}$, G. Lukina ${ }^{2}$, G. Gridneva', S. Glukhova ${ }^{1}$, A. Kudryavtseva ${ }^{1}$. 'V. A. Nasonova Research Institute of Rheumatology, Moscow, Russian Federation; ${ }^{2}$ Moscow Clinical Scientific Center named after Loginov A. S., Moscow, Russian Federation

Objectives: To investigate predictors of drug survival of bDMARDs in previously bio-naive patients (pts) with RA during the first year of therapy.

Methods: 204 adult bio-naive pts (173 women, $84.8 \%$ ), with active RA, despite the concomitant DMARD therapy, were included into retrospective study. All of them initiated bDMARDs: infliximab (INF) - 65 pts $(31.9 \%)$, rituximab (RTM) - 39 (19.1\%), adalimumab (ADA) - 30 (14.7\%), etanercept (ETA) - 28 (13.7\%), abatacept (ABA) - 23 (11.3\%), tocilizumab (TZ) - 15 (7.4\%), certolizumab pegol - 4 (1.9\%). The following indicators were used as survival predictors: sex, age and clinical form of RA. Pts were divided by age according to the classification adopted by the World Health Organization: $18-44$ years ( 74 pts), $45-59$ years (68 pts), 60-74 years (57 pts), 75 years or more (5 pts). Clinical forms of RA were presented: RA, seropositive by rheumatoid factor (RF), RA, seronegative by RF, RA with extra-articular manifestations, adult-oneset Still's disease, juvenile RA. Predictors of therapy inefficiency or AE were investigated in Cox proportional risk model. Survival on drug was estimated using the Kaplan-Meier method and evaluation of difference significance using logrank criterion.

Results: A year later, 92 pts (45\%) remained on bDMARDs and 112 pts had their treatment discontinued. The reasons of bDMARDs discontinuation during the first year of treatment were: lack of effectiveness (including primary inefficiency) $-50 \%$, adverse events (AE) - $25 \%$, administrative causes - $17 \%$, remission $-6.25 \%$, death due to reasons unrelated to the therapy $-1.75 \%$. By the end of the observation period, the best survival was shown by RTM therapy $(69.23 \%$ of patients continued treatment for a year), ETA (44.4\% of patients) and ABA ( $43.48 \%$ of patients). Discontinuation of bDMARDs due to remission was achieved in 7 patients and proved to be significantly higher in the RTM group $(10.26 \%, p<0.05)$ compared to the ABA group $(8.7 \%)$ and ADA group (3.45\%). Although the number of women continued after a year was significantly higher than that of men $(84.8 \%$ and $15.2 \%$ respectively), female sex was not a reliable predictor of drug survival. At the same time, the rate of discontinuation due to $A E$ in women was higher $(96.55 \%, p=0.03)$. After a year, the number of pts continuing treatment in all age groups remained comparable, and the difference between them - statistically not significant: 1 group (18-44 years old, 29 pts) $-31.52 \%$ of pts, 2 group (45-59 years old, 36 pts) $-39.13 \%, 3$ group (60-74 years old, 26 pts) $-28.26 \%$, 4 group (75-90 years old, 1 pts). Discontinuation of bDMARDs due to inefficiency was noted in 1 group more often $(46.43 \%, 26$ pts, $p=0.03)$, in other groups this indicator was $33.93 \%$ (19 pts) in the 2nd group, $19.64 \%$ (11 pts) in the 3 rd group and $0 \%$ in the 4 th group. Discontinuation therapy due to $\mathrm{AE}$ was also prevalent in 1 group (50\%, 14 pts) than in $2(14.3 \%, 4$ pts), 3 (32.1\%, 9 pts) and 4 (3.6\%, 1 pts). Discontinuation of therapy due to inefficacy was more common in the group of seronegative RA - 59.1\% ( $p<$ 0.05). In the seropositive RA group $24.8 \%$ of pts had interrupted bDMARDs for this reason, in the RA with extra-articular manifestations group it was $18.1 \%$, in the adult-oneset Still's disease group - $30 \%$ and in the juvenile RA group - $30 \%$. Discontinuation of therapy due to remission was overwhelmingly observed in seropositive RA group (6 pts, 4\%) and was significantly higher than in other groups (1 patient in RA with extra-articular manifestations group, $4.5 \%$ )

Conclusion: Female sex, young age (18-44 years), RA, seronegative by RF were associated with less survival of bDMARDs due to lack of effectiveness and or $A E$, and RTM and seropositive RA - with more frequency of discontinuation of therapy due to remission.

Disclosure of Interests: Eugenia Aronova: None declared, Galina Lukina Speakers bureau: Novartis, Pfizer, UCB, Abbvie, Biocad, MSD, Roche, Galina Gridneva: None declared, Svetlana Glukhova: None declared, Anastasia Kudryavtseva: None declared

DOI: 10.1136/annrheumdis-2020-eular.1140

\section{AB0274 USE OF TNF-INHIBITORS BIOSIMILARS IN CHRONIC INFLAMMATORY ARTHRITIDES: A THREE-YEAR EXPERIENCE IN A LARGE MONOCENTRIC COHORT OF PATIENTS FROM THE NORTH-EAST ITALY}

D. Astorri ${ }^{1}$, F. Ometto ${ }^{2}$, L. Friso ${ }^{2}$, B. Raffeiner ${ }^{2}$, C. Botsios ${ }^{2}$, A. Doria ${ }^{2}$.

${ }^{1}$ Rheumatology Unit, University of Padova, Padova Hospital, Department of Medicine - DIMED, University of Padova, Padova Hospital, Padova, Italy; ${ }^{1}$ Rheumatology Unit, University of Padova, Padova Hospital, Department of Medicine - DIMED, University of Padova, Padova Hospital, Padova, Italy

Background: In recent years several biosimilars (BS) of tumour necrosis factor inhibitors (TNF-i) were introduced. At the Padova University Hospital the first BS of etanercept (bsETN) was available in October 2016 and the BS of adalimumab (bsADA) was available in November 2018.

Objectives: The objectives of the study were to evaluate the rate of bioriginator-biosimilar (BO-BS) switch in all patients with rheumatoid arthritis (RA), psoriatic arthritis (PSA) and axial spondiloarthritis (axSpA) in the cohort of the Padova University Hospital and to examine factors favouring BO-BS switch. Secondly, we investigated survival of BO-BS switch and BO treatment and factors associated with longer treatment survival.

Methods: We considered all patients on ETN originator (boETN) treatment when the first bsETN was available (1st October 2016) and all patients on ADA originator (boADA) when bsADA was available (1st November 2018). Patients were followed until 30 August 2019 and were classified as BO-BS switchers if they underwent a switch from either boETN or boADA to BS during the follow-up, otherwise they were considered as continuing BO treatment. Factors associated with BO-BS switch were tested with a multivariable regression analysis. To test the survival of the BO-BS switch and of the $\mathrm{BO}$ treatment, Cox regression analysis was used including all variables achiving a $p<0.10$ in univariate analysis tested with Log-rank test and Kaplan-Meier curves.

Results: Among 1208 patients (553 RA, 433 PSA, 215 axSpA), 560 (46.3\%) patients switched to bsETN (391) or bsADA (169). Mean disease duration was 16 (14.2) years and mean duration of the bDMARD treatment was $96.3(56.8)$ months. After adjustment for potential confounders, factors associated with BO-BS switch were a longer disease duration, a shorter duration of previous bDMARD treatments and diagnosis (Tab.1) RA patients had almost a 3 fold increased likelihood of being switched to BS compared to PSA and axSPA, while difference between PSA and axSPA was not significant.

Following Cox regression analysis we observed a longer drug survival in $\mathrm{BO}-\mathrm{BS}$ switchers compared to those continuing with BO (HR 1.38; 95\% C.I. 1.2-1.58; $\mathrm{p}<0.001$ ) (Fig. 1). A longer drug survival was also associated with a longer disease duration ( $\geq 15 y$ years: HR 1.75 ; $95 \%$ C.I. 1.5-2; $p<0.001$ ), longer mean duration of previous bDMARDs ( $\geq 5$ years: HR $4.1 ; 95 \%$ C.I. $3.5-4.7 ; p<0.001$ ), and diagnosis (RA vs PSA: HR 1.22; 95\% C.I. 1.02-1.47; $p=0.030$; RA vs axSpA: HR 0.89 95\% C.I. 0.067-0.97; $p=0.023$; PSA vs axSpA: HR 0.66; 95\% C.I. 0.57-0.77; $\mathrm{p}<0.001$ ) (Fig 2).

Conclusion: BO-BS switch was undertaken in almost half of the patients. Patients with longer disease duration and longer bDMARD duration, were the most likely to be switched successfully to BS. BO-BS switching does not affect the survival of the treatment, indeed, it provides sustained effectiveness particularly if undertaken in patients with stable disease activity. 
Table 1. Factors associated with BO-BS switch, multivariate regression analysis.

\begin{tabular}{lccl}
\hline & & OR (95\% C.I.) & p value \\
\hline Age & per 10 years increase & $1.11(0.98-1.25)$ & 0.102 \\
Disease duration & per 5 years increase & $1.19(1.08-1.32)$ & 0.01 \\
Mean time on bDMARD & per 1 year increase & $0.71(0.66-0.77)$ & $<0.001$ \\
$\mathrm{HAQ}^{*}$ per 1 unit increase & & $1(1-1)$ & 0.68 \\
Gender (male) & $1.07(0.74-1.56)$ & 0.71 \\
Disease diagnosis & & $<0.001$ \\
RA vs PSA & $2,70(1,79-4,07)$ & $<0,001$ \\
RA vs axSPA & $2,77(1,62-4,72)$ & $<0,001$ \\
PSA vs axSPA & $1,03(1,62-4,72)$ & 0,925 \\
csDMARD combination & & $0.77(0.54-1.11)$ & 0.167 \\
Model Constant & & $<0.04$ \\
\end{tabular}

OR odds ratio, C.I. confidence interval, ${ }^{*}$ at the time the biosimilar of the ongoing originato was available.

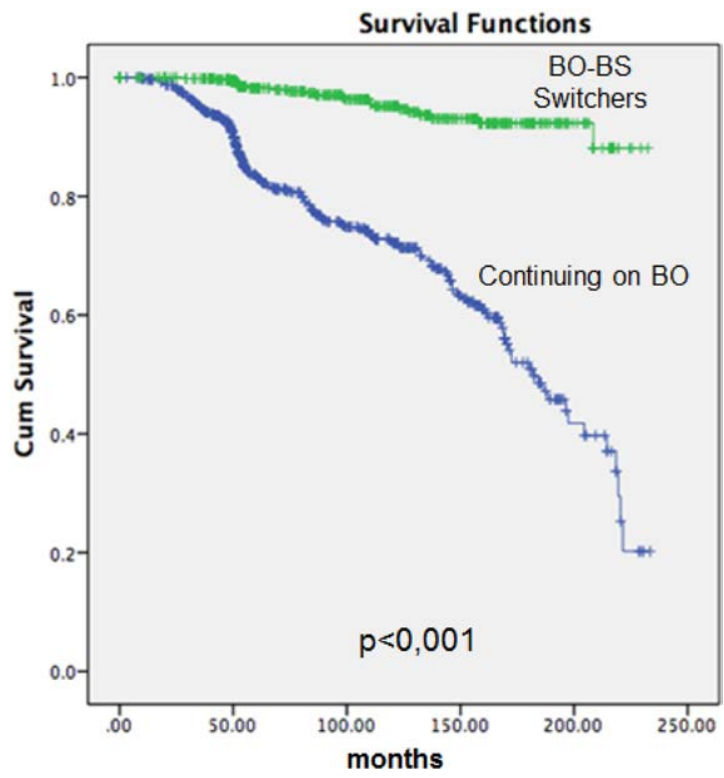

Figure 1. Kaplan-Meier curves for treatment survival, Log-rank test.

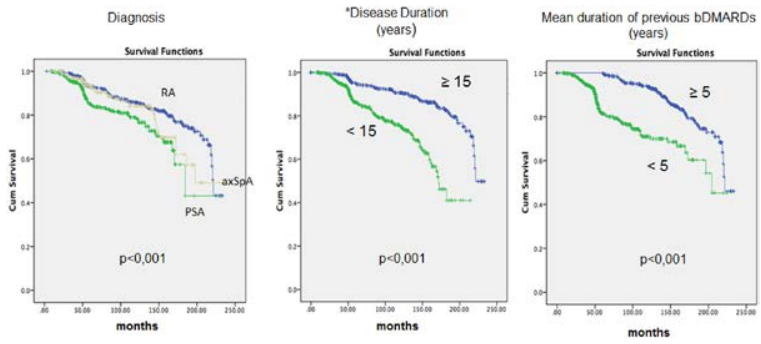

Figure 2. Kaplan-Meier curves for treatment survival in all patients, Log-rank tes

Disclosure of Interests: DAVIDE ASTORRI: None declared, Francesca Ometto: None declared, LARA FRISO: None declared, BERND RAFFEINER: None declared, Costantino Botsios: None declared, Andrea Doria Consultant of: GSK, Pfizer, Abbvie, Novartis, Ely Lilly, Speakers bureau: UCB pharma, GSK, Pfizer, Janssen, Abbvie, Novartis, Ely Lilly, BMS

DOI: 10.1136/annrheumdis-2020-eular.4898

\section{AB0275 \\ COMPARATIVE EFFICACY (DAS 28) OF TOCILIZUMAB AND OTHER TARGETED IMMUNE MODULATORS (TIMS) FOR RHEUMATOID ARTHRITIS: A NETWORK META-ANALYSIS (NMA)}

J. H. Best ${ }^{1}$, J. Uyei ${ }^{2}$, J. Dang ${ }^{1}$, Y. Jiang ${ }^{2}$, R. Singh ${ }^{3}$, P. Bilir ${ }^{2}$, A. Karabis ${ }^{4}$, J. Munakata ${ }^{2}$, W. Reiss ${ }^{1} .{ }^{1}$ Genentech, Inc., South San Francisco, United States of America; ${ }^{2}$ QVVIA, San Francisco, United States of America; ${ }^{3} I Q V I A$, Mumbai, India: ${ }^{4}$ IQVIA, Amsterdam, Netherlands

Background: With a 'treat to target' approach in RA, guidelines recommend tailored monitoring of disease activity using validated composite instruments, such as the disease activity score (DAS) 28 . While response assessment at 24 weeks is the standard in clinical trials, assessment as early as 12 weeks is

recommended. There is limited evidence assessing the relative efficacy of TIMs following a 'treat to target' strategy.

Objectives: To evaluate the relative efficacy of intravenous (IV) and subcutaneous (SC) tocilizumab plus a conventional disease modifying antirheumatic drug (cDMARD) to other TIMs plus a cDMARD in TIM-naïve or mixed (<20\% TIM-experienced) adults with moderate to severe RA. Efficacy was defined as achieving remission according to a DAS28 score $<2.6$ at 12 and 24 weeks.

Methods: Randomized controlled trials (RCTs) were selected from a recent systematic literature review conducted by the Institute for Clinical and Economic Review (ICER), as well as from trials for upadacitinib (SELECT-NEXT, SELECT-COMPARE), which were not included in the ICER 2017 report. RCTs that compared TIMs to each other or placebo were included. Treatments included Janus kinase (JAK) inhibitors (upadacitinib, baricitinib, and tofacitinib), tumor necrosis factor alpha inhibitors (TNFi; adalimumab, certolizumab pegol, golimumab, and infliximab), and other non-TNFis (rituximab, sarilumab, tocilizumab, and abatacept). A Bayesian NMA was performed in OpenBUGS and R using a fixed effects model. Model selection was based on deviance information criterion. Forest plots of odds ratios (OR) are presented.

Results: In the 12-week analysis, 15 trials were included with a pooled study population of 9,154 patients. Populations were similar across trials and predominantly female (mean $78 \%$, range $39-87 \%$ ), with a baseline mean age of 52 years (range 47-56), mean disease duration of 8 years (range 2-11), and mean DAS28 score of 6 (range 5-7). In the 12-week analysis, compared to CDMARD, all TIMs were more likely to achieve remission (statistically significant), but tocilizumab IV showed a substantially greater magnitude of effect $(\mathrm{OR}=19.3,95 \% \mathrm{Crl}=10.99,37.22)$ which was consistent with raw trial results (Figure 1). In pair-wise comparison, tocilizumab IV was associated with a greater likelihood of achieving remission compared to abatacept IV (OR=7.47, $\mathrm{Crl}=2.53,20.89)$, abatacept SC $(\mathrm{OR}=4.29, \mathrm{Crl}=1.96,9.94)$, baricitinib $(\mathrm{OR}=3.39, \mathrm{Crl}=1.74,7.09)$, adalimumab $(\mathrm{OR}=5.10, \mathrm{Crl}=2.68,10.42)$, tofacitinib (OR=5.44, Crl=1.26, 20.57), upadacitinib $15 \mathrm{mg}(\mathrm{OR}=3.23, \mathrm{Crl}=1.72$ 6.54), and upadacitinib 30mg (OR=4.05, $\mathrm{Crl}=1.97,8.85)$.

In the 24-week analysis, 21 trials were included in the analysis with a pooled study population of 12,180 patients. Patient characteristics were the same as the 12 week analysis. Compared to CDMARD, all TIMs were more likely to achieve remission (statistically significant), with tocilizumab IV and SC showing a greater magnitude of effect $(\mathrm{OR}=12.08, \mathrm{Crl}=8.09-18.30$ and $\mathrm{OR}=11.98, \mathrm{Crl}=5.17-35.86$, respectively) (Figure 2). In pair-wise comparison, tocilizumab IV and SC were associated with a greater likelihood of achieving remission compared to abatacept IV, adalimumab, baricitinib, infliximab, upadacitinib $15 \mathrm{mg}$, and sarilumab. Conclusion: Results of this NMA demonstrate that tocilizumab is associated with a greater likelihood of remission (DAS28 <2.6) at 12 and 24 weeks compared to most other TIMs including new JAK inhibitors, when used in combination with a cDMARD among TIM-naïve/mixed patient populations.

Figure 1. DAS28 at 12 weeks-All TIMs were more likely to achieve remission compared to cDMARD, but tocilizumab IV showed a substantially greater magnitude of effect that was consistent with raw trial data*

\section{DAS28 12 weeks}

Comparison

TCZiv+cDMARD vs. CDMARD

GOLsC+CDMARD vs. CDMARD

IFX+CDMARD vs. CDMARD

TCZsc+CDMARD vs. CDMARD

UPA $15+$ +CDMARD vs. CDMARD

BAR+CDMARD vs. CDMARD

UPA30+CDMARD vs. CDMARD

ABTsc+CDMARD vs. CDMARD

ADA+CDMARD vs. CDMARD

TOF+CDMARD vs. CDMARD

ABTiv+cDMARD vs. CDMARD
OR (median) $95 \% \mathrm{Crl}$

$19.30(10.99,37.22)$

11.98 ( $5.29,33.03)$

$8.70(2.10 .41 .86)$

$8.64(3.97 .22 .81)$

$5.98(4.53,7.92)$

$5.68(4.03,8.07)$

$4.77(3.07,7.43)$

$4.51(2.61,7.84)$

$3.79(2.81,5.12)$

$3.54(1.13,13.60)$

$2.62(1.16,6.45)$

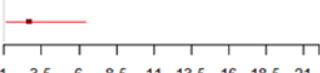

$\begin{array}{lllllllll}1 & 3.5 & 6 & 8.5 & 11 & 13.5 & 16 & 18.5 & 21\end{array}$

<-Favors comparator Favors intervention-> 